\title{
Archipiélago juvenil: jóvenes indígenas y cultura digital*
}

\author{
Youth archipelago: indigenous students and digital culture \\ Arquipélago Juvenil: jovens indígenas e cultura digital
}

Jorge Alberto Meneses Cárdenas ${ }^{\text {a }}$

DOI: https://doi.org/10.11144/Javeriana.uh89.ajji

Universidad del Mar, México

jorgemenecs@hotmail.com

ORCID: https://orcid.org/0000-0002-8553-8082

Recibido: 30 Noviembre 2019

Aceptado: 27 Septiembre 2020

Publicado: 20 Diciembre 2020

\section{Resumen:}

El artículo se enfoca en la cultura digital de jóvenes universitarios indígenas en México y Colombia. A través de una etnografía digital multisituada, presento un mosaico de prácticas y saberes juveniles derivadas de sus experiencias sociodigitales. El tránsito por distintas islas de socialidad me permitió conocer sus saberes, tanto en sus intercambios cara a cara como en la plataforma Facebook. Lejos de pensar que la vida digital está aislada de los microcontextos, los distintos flujos de sentido y las prácticas son resultado de la imbricación entre lo presencial y la copresencia digital. Por esa razón, utilicé herramientas híbridas con el objetivo de ubicar los flujos de sus culturas digitales. Metafóricamente, se puede afirmar que los jóvenes habitan un archipiélago juvenil desde donde se conectan a sus muros para alojar y dinamizar hipernarrativas. Precisamente, los resultados muestran trayectorias biográficas desiguales, y repertorios y prácticas sociodigitales con saberes multirreferenciales.

Palabras clave: jóvenes universitarios indígenas, archipiélago juvenil, cultura digital, Facebook.

\begin{abstract}
:
This article focuses on the digital culture of indigenous university students in Mexico and Colombia. Through a multisite digital ethnography, I present a mosaic of youth practices and knowledge derived from their socio-digital experiences. The transit through different islands of sociality allowed me to learn about their knowledge, both in their face-to-face exchanges and on the Facebook platform. Far from thinking that digital life is isolated from microcontexts, the different flows of meaning and practices are the result of the interweaving of face-to-face and digital co-presence. For that reason, I used hybrid tools with the aim of locating the flows of their digital cultures. Metaphorically, it can be stated that young people inhabit a youth archipelago from where they connect to their walls to host and dynamize hypernarratives. Precisely, the results show unequal biographical trajectories, and sociodigital repertoires and practices with multi-referential knowledge.
\end{abstract}

Keywords: Indigenous university students, youth archipelago, digital culture, Facebook.

\section{Resumo:}

$\mathrm{O}$ artigo enfoca a cultura digital de jovens universitários indígenas no México e na Colômbia. Por meio de uma etnografia digital multissituada, apresento um mosaico de práticas e saberes juvenis derivados de suas experiências sócio-digitais. $\mathrm{O}$ trânsito por diferentes ilhas de sociabilidade permitiu-me conhecer os seus saberes, tanto nas suas trocas presenciais como na plataforma do Facebook. Longe de pensar que a vida digital está isolada dos micro-contextos, os diferentes fluxos de sentido e práticas são o resultado da sobreposição entre a copresença face a face e a digital. Por isso, usei ferramentas híbridas para mapear os fluxos de suas culturas digitais. Metaforicamente, pode-se afirmar que os jovens habitam um arquipélago juvenil de onde se conectam às suas capas para abrigar e dinamizar hiper-narrativas. Justamente, os resultados mostram trajetórias biográficas desiguais, repertórios e práticas sócio-digitais com saberes multirreferenciais.

Palavras-chave: jovens universitários indígenas, arquipélago juvenil, cultura digital, Facebook.

Notas de autor

${ }^{a}$ Correo de correspondencia: jorgemenecs@hotmail.com 


\section{Introducción}

En América Latina, las juventudes se pueden clasificar analíticamente en dos: las que están conectadas a Internet, pero también a las instituciones familiares, escolares y laborales, y las que están desconectadas de estas últimas (Reguillo, 2010; Urteaga, 2011). Este hallazgo me animó a conocer trayectorias concretas para visibilizar los saberes y las prácticas sociodigitales de jóvenes universitarios indígenas. Dichas trayectorias condensan la cultura digital, es decir, la infraestructura tecnológica que les permite la conectividad, los artefactos digitales que usan y apropian para esto y los sentidos que se construyen al estar siendo internautas situados.

¿Cuál es la cultura digital de las y los jóvenes universitarios ${ }^{1}$ indígenas y afrodescendientes? Para responder esa pregunta, contemplo cuatro elementos. El primero es delimitar el espacio de observación en dos universidades: la Universidad del Mar, en Huatulco, y la Universidad de La Guajira, en Riohacha. En el contexto mexicano, la primera acoge a zapotecos, mixes, mixtecos, tacuates y afrodescencientes; mientras que en el colombiano, la segunda cuenta con estudiantes wayuus, wiwas y afrodescendiantes. El segundo pretende evitar la sobrerrepresentación de jóvenes varones; por esa razón, conviví con hombres y mujeres heterosexuales y homosexuales en diversas islas de socialidad. El tercer elemento se asocia con la comprensión de que la cultura digital se construye mediante flujos de sentido multirreferenciales y dinámicos. Además, que la cultura digital no está aislada de procesos locales en los que ocurren situaciones de desigualdad y nuevas distinciones sociales (Reygadas, 2004). El cuarto elemento considera la delimitación del análisis de prácticas y sentidos de la cultura digital en la plataforma Facebook y su relación con las islas de socialidad, con el propósito de situar las prácticas universitarias indígenas como experiencias contemporáneas de la condición juvenil.

$\mathrm{Si}$ bien, las culturas digitales tienen una base material, se construyen mediante prácticas cognitivas, valorativas y afectivas que condensan capitales digitales heterogéneos en contante resignificación. Las apropiaciones juveniles permiten ubicar sus repertorios, desigualdades y procesos identitarios múltiples, porque los jóvenes son agentes que construyen prácticas y significados sobre la vida digital en la cotidianidad. Construyen saberes reflexivos y lúdicos, a través de experiencias de interacción digital performativas y no simples mensajes unilineales. No se puede olvidar, además, que las conexiones en línea se producen con artefactos digitales, cuyos sistemas operativos filtran la realidad, y extraen los datos de los usuarios como moneda de cambio para el mercado.

El artículo se organiza en los siguientes apartados: presento la propuesta de un archipiélago juvenil como una metáfora que condensa espacios y prácticas juveniles articulados con sus culturas digitales. Posteriormente, caracterizo de las y los jóvenes universitarios y describo el método etnográfico con el que me acerqué a sus prácticas. Es importante destacar que combino la experiencia etnográfica presencial y de copresencia digital en la plataforma Facebook, para visibilizar repertorios, distinciones y flujos de interacción que dan sentido al dinamismo de sus culturas digitales. Finalizo con algunas reflexiones acerca de las prácticas y los saberes de las y los jóvenes universitarios indígenas en México y Colombia, respectivamente.

\section{Archipiélago juvenil}

El archipiélago juvenil es una metáfora ${ }^{2}$ que articula los microespacios fronterizos con las plataformas sociodigitales, a través de múltiples experiencias juveniles. La conectividad sociocultural se dinamiza por las interacciones entre los universitarios indígenas con afrodescendientes y mestizos. Esto implica situar sus conexiones de sentido según los ritmos expresados en flujos sociales contemporáneos, que se están dando a través de socialidades cara a cara y en la copresencia digital (Fig. 1). 


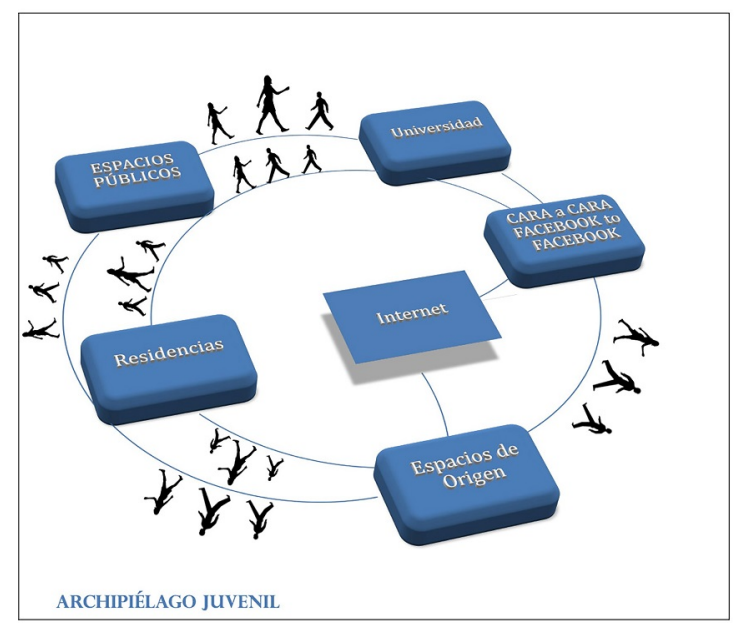

FIGURA 1.

Archipiélago juvenil

Fuente: elaboración propia.

La escuela, la casa, el trabajo, los lugares de origen y los espacios públicos, así como múltiples espacios de tránsito no son espacios aislados ni entre sí, ni de las plataformas digitales. Estos constituyen esferas socioculturales interconectadas porque los jóvenes dinamizan los saberes que allí se albergan, a través de intercambios que generan saberes emergentes multirreferenciales y transculturales. Las islas de socialidad juvenil no son homogéneas ni aparecen aisladas ${ }^{3}$, debido a que forman arenas sociales que se sedimentan con las interacciones cotidianas en situaciones concretas. Cada isla tiene relación con las otras, precisamente, el motor de los dinamismos es la agencia compartida de los jóvenes (Lasén y Puente, 2016), quienes se posicionan según situaciones, actores en relación y espacios. De esa manera, sus prácticas y saberes culturales se construyen a partir de tres dimensiones: a) contextuales-situacionales-temporales; b) materiales-digitalestecnológicas; $\mathrm{y}, \mathrm{c})$ personales-grupales-posicionales.

Estas tres dimensiones ubican lo cultural desde espacios fronterizos de interacción, habitados, apropiados y construidos sociodigitalmente con tránsitos, intercambios y préstamos transculturales performativos. Esta situación de tránsito e intercambio se refleja en experiencias de género, clase, etnicidad y generacionales, dinamizadas desde posiciones sociales concretas como la de estudiante, pareja, hijo, compañero, migrante, internauta y demás posiciones. Además, los ritmos juveniles son multisecuenciales y están trastocando los ritmos "disciplinarios" de las instituciones, como los de la familia y la escuela.

Por último, en términos estructurales la noción de archipiélago juvenil no reduce cada isla a una representación en escala de lo global, más bien, son microcontextos transfronterizos con flujos sociales en tránsito. Esta noción no es una metáfora de una estructura uniforme, se acerca más a lo que representa en forma literal: un conjunto de islas diferentes que se sedimentan y cambian como parte de un proceso provocado por las olas juveniles. En este caso, algo que articula a los jóvenes es que también transitan por la plataforma Facebook como una nueva experiencia performativa traslapada con otras tantas en su vida cotidiana.

\section{El método etnográfico}

Para hacer operacionalizable el archipiélago juvenil, contacté a jóvenes de una generación bisagra, situados en este grupo debido a que son quienes llevan y traen códigos socioculturales híbridos, tanto en lo digital como 
en las islas de socialidad donde transitan de forma presencial. Al no ser homogéneos, el género, la clase, la etnicidad y la generación se viven como experiencias concretas. En las situaciones específicas se experimenta el ser mujer, hombre o cualquier otro género, de una manera particular (Lagarde, 2011). De la misma manera, la clase es una experiencia concreta (Saraví, 2015), hoy en día los capitales digitales muestran nuevas distinciones y desigualdades sociales (Reygadas, 2004). Asimismo, la etnicidad se vive en los usos (Martín-Barbero, 2002), y la generación no alude a la edad, sino a experiencias compartidas y concretas, a una cita concertada (Lasén, 2000).

Para ubicar sus prácticas y sentidos en Facebook, planteé la etnografía multisituada (Hine, 2004) con herramientas híbridas (Rogers, 2013), dado que el trabajo de campo presencial y la copresencia digital estuvieron traslapados. del objetivo era conocer experiencias juveniles desde diversas islas de socialidad en den el periodo 2015-2017. Retomé la propuesta de clasificación de los métodos digitales de Rogers (2009), que los divide en extractivos y observativos, y opté por los segundos. La observación participante, como forma de arranque etnográfico, me permitió navegar en Facebook como lo hacen los internautas; por ejemplo, mirar en muro ajeno es también participar.

Luego, apropié la plataforma como un archivo vivo para extraer datos, y para interactuar con los internautas, bajo el paraguas metodológico propuesto por Janet Salmons (2016). La autora señala que los datos digitales se pueden clasificar entre los existentes, que están relacionados con la metáfora de un minero que escarba para ver qué encuentra, y los provocados, que asocia al etnógrafo con el jardinero, porque cultiva datos, en el sentido de que los provoca con sus interacciones con la intención de que los usuarios reflexionen sobre lo que dicen y hacen en la red.

Si la minería es una estrategia asincrónica en la medida en que se puede regresar al archivo, el cultivo de datos etnográfico es sincrónico porque se pregunta de ida y vuelta. Entonces, Facebook es un archivo vivo, donde se escribe sobre lo escrito, como los palimpsestos (Martín-Barbero, 2002).

Bajo esta postura, esta plataforma es un campo etnográfico digital, debido a que allí ocurren interacciones situadas. Además, esta alberga múltiples repertorios que van siendo parte de la biografía digital de los usuarios. El estar conectado etnográficamente permite el acceso al metadato ${ }^{4}$, en general, pero se complementa con la triangulación de datos recolectados cara a cara sin la intención de verificar "verdades", sino de construir reflexividades basadas en las conexiones de sentido de las personas.

A partir de la experiencia etnográfica digital, es posible profundizar en la apropiación de artefactos, las propiedades del sistema algorítmico y la intencionalidad del usuario. El arraigo digital en línea (Rogers, 2009, 2013) se entiende en la experiencia etnográfica (Hine, 2004; Pink et al., 2016); en este caso, como una experiencia compartida con jóvenes universitarios indígenas y afrodescendientes. De eso se trata el ejercicio que presento, un aprendizaje colaborativo con los participantes, y una actualización acerca de las propiedades y los cambios de cada plataforma para su apropiación etnográfica.

\section{Los inicios en Facebook}

En ambas comunidades universitarias, la mayoría de las iniciaciones en Facebook están situadas entre el 2010 y el 2014, periodicidad relacionada con sus ciclos temporales en la educación secundaria y el bachillerato. También, encontré los opuestos: quienes comenzaron antes del 2010 y quienes lo hicieron más recientemente, en el 2017.

Las motivaciones de inicio en los estudiantes de la Universidad del Mar muestran lo siguiente: "porque me gustaba una chava" (universitario zapoteca); "para estar conectado con amigos" (universitario tacuate); "porque lo usaban todos" (universitaria mixe); "el que me dijo fue mi hermano, para que buscara gente que no veía” (universitario mixteco); “en la universidad, para compartir archivos" (universitaria zapoteca); "en la universidad, para las tareas y buscar amigos" (universitario zapoteco). 
Por su parte, los estudiantes de la Universidad de La Guajira mencionan las siguientes motivaciones de inicio en la plataforma: "porque un primo me lo abrió" (universitaria wayuu); "porque en el colegio todas tenían" (universitaria afrodescendiente); "porque fui a visitar a unos primos que tenían" (universitario wayuu); "para poder estar con las hembritas" (universitario wayuu); "para no quedarme atrás de los compañeros de la uni [universidad]" (universitario wayuu).

Ahora bien, las biografías digitales permiten identificar que las iniciaciones en Internet tienen tres rasgos comunes: a) la precariedad estructural en sus escuelas, pues no había suficientes computadoras con respecto al número de estudiantes, no tenían garantía de acceso a Internet para navegar, y el tiempo de inmersión era insuficiente; b) los instructores enseñaban la teoría separada de la práctica, lo que imposibilitaba descubrir las funciones de forma inductiva. Mientras que en los cibercafés sí se practica entre pares de manera lúdica; c) la brecha digital se ensancha por la brecha de control sociodigital, es decir, se controlaba lo que los estudiantes consultaban, pues había prohibiciones de inmersión a páginas de "ocio".

Esto es importante porque el juicio al uso de Internet por ocio no se quedó en las aulas de secundaria. En las computadoras de la sala de informática de la Universidad del Mar, la plataforma Facebook está bloqueada en horas de clase ( 8 a 13 horas y 16 a 19 horas), para evitar pérdida de tiempo en esa red social.

En dicha postura subyace una lógica de productividad capitalista, según la cual el tiempo es lineal y vacío (Lasén, 2000), se asume que el tiempo es oro como para desperdiciarlo en banalidades. Sin embargo, estar desconectado de Facebook es una desventaja porque también es apropiada como un espacio donde circulan materiales e información para clases y eventos cotidianos de la universidad.

La posibilidad de habilitar el celular propio para oponerse a la prohibición pone en desventaja a quien no tiene datos, tiene uno analógico o el celular no tiene espacio para bajar los archivos que se requieran, lo cual muestra experiencias de clase desiguales (Saraví, 2015). Esas experiencias van articuladas con carencias familiares-personales, en cuanto a posesión de computadoras, celulares y señal de Internet en los espacios de origen y en las residencias universitarias donde habitan. Sin olvidar que, en ambas universidades, muchos son jóvenes que han migrado para extender su escaloraridad.

\section{Los amigos y la familia}

La noción de amigos en Facebook cambia la forma en la que se entiende la amistad (Van Dijk, 2016). Desde la lógica del algoritmo, la proximidad del contacto depende de las interacciones que se tengan, independientemente de su contenido. En cuanto a la cercanía en términos subjetivos, no se puede afirmar que los internautas indígenas ni afrodescendientes guarden un patrón del tipo de amigos ni de los grupos en los que están inmersos en la plataforma Facebook. Pero sí existe una característica compartida, en sus interacciones digitales destacan tanto excompañeros de clase como de la universidad, hermanos y primos.

En el devenir cotidiano comparten hipernarrativas múltiples: memes, fotos, situaciones del pasado, múltiples interacciones del momento y futuros viajes escolares o viajes de retorno a sus pueblos. En términos generacionales, esto es importante, pues devela el uso y la apropiación de la plataforma como un espacio donde se amplían sus formas de estar juntos, pero también se muestran diferencias generacionales.

Por ejemplo, la diferencia generacional se puede observar en la relación con sus familiares. En repetidas ocasiones, era visible que cuando subían fotos de su infancia, en fiestas, cumpleaños o en momentos de ocio, se movilizaban las relaciones de parentesco. Cuando los protagonistas de esas imágenes eran ellos y ellas con sus padres, abuelos y la familia extensa, las personas que reaccionaban a las publicaciones eran sus hermanos, primos y sobrinos. Eso muestra un juego de conexiones y desconexiones intergeneracionales, ya que mientras sus familiares mayores eran los protagonistas de las fotos o las personas que las tomaron, no fueron quienes las digitalizaron, ni quienes comentaron esos recuerdos, sino sus pares generacionales. 
Esto no es una inferencia, constaté en los comentarios posicionamientos familiares: "muy buena esa, primo", "saludos tío, bonito recuerdo", e incluso de sus mismos compañeros de la universidad "iqué te pasó? [...], estabas bonito".

Además, como nueva generación, es la encargada de instruir a sus familiares mayores en el uso del celular inteligente, así como en la apropiación de WhatsApp y Facebook.

Incluso, en alguna ocasión una joven umareña posteó un meme escrito en mixe - con la traducción en español en la parte de abajo- sobre la diferencia entre el amor y la pasión. Tanto su hermana como otros jóvenes escribieron que la traducción no era exacta o que por lo menos que no era así en la región de donde eran. Apropiaron la plataforma para reafirmar autoadscripciones de identidad (Ricaurte y Ortega, 2010), al estar insertos en los flujos generacionales en su tiempo lúdico.

\section{El número de contactos}

Aunque encontré diversos ritmos digitales, uno que indica la agencia juvenil es la autosincronización (Lasén, 2000), es decir, cada quién se apropia de la plataforma según sus necesidades, la demanda de sus amigos y la isla de socialidad donde se encuentre. Existen islas privilegiadas para la conexión: las residencias universitarias que cuentan con Internet.

Con respecto al número de amigos, encontré que entre universitarias de La Guajira están los extremos. Mientras una mujer wayuu tenía más de 2000 amistades, otra de la misma etnicidad tenía menos de 100. El número de amigos coincidió con las grandes diferencias en las fechas en que abrieron su perfil: la primera antes del 2010 y la segunda hasta el 2017.

La primera es originaria de Uribia, tiene computadora desde los 15 años y en su etapa universitaria ha vivido en una pensión que cuenta con Internet. En su biografía digital los artefactos digitales han existido desde temprana edad y, en su etapa universitaria, no solamente el celular y la computadora son distinciones superficiales, pues el hecho de poseerlos le permite trabajar en casa sin necesidad de ir a cibercafés. Además, se comunica de forma diferenciada con su familia. Con su padre lo hace mediante llamadas vía celular, con su madre por videollamadas en Skype, y con su hermana menor, a través de la mensajería de WhatsApp. Esta plataforma la habilita para mensajes de texto, audio e imágenes, en un ritmo que privilegia el presente continuo entre pares más que para llamadas. Con sus padres, se contacta en momentos específicos: con su padre para pedir el dinero que necesita para la renta, y con su madre para avisar si irá a casa o para algún asunto personal.

Por su parte, la segunda universitaria vive en casa de un hermano y su familia, pero no cuenta con Internet. Ella tuvo celular hasta la universidad por un regalo que recibió de una amiga extranjera que se hospedó en su ranchería. Sin embargo, "su" celular es de tiempo compartido porque lo debe prestar a su hermano, que es guía turístico y no cuenta con un aparato de "alta gama" para fotografías. Ella vive experiencias de desventaja debido a que no tiene computadora, ni recursos económicos para un cibercafé; tampoco dispone de una computadora en su universidad, pues aunque tiene acceso a las salas de cómputo, no puede acceder a una por mucho tiempo.

$\mathrm{Al}$ vivir con su hermano, entra a un circuito de reciprocidad que la deja en desventaja en su posición de estudiante. El celular tiene un valor de uso para ambos, pero el intercambio se impone de acuerdo con una obligación del tipo de relación social que lo genera (Bensa, 2015). En este caso, prestar el celular le otorga crédito al interior de su casa familiar, ya que al no generar entradas económicas debe "poner de su parte" para el bien común. Por eso, lo importante de esta transacción es comprender las circunstancias que la obligan a prestarlo, más que visibilizar la reciprocidad por parentesco. 


\section{Las fotos de perfil y de portada}

Una de las características de Internet es el mosaico de imágenes que se alojan en distintas plataformas. En el caso de los perfiles de Facebook, las fotos de perfil y de portada muestran diversidad de autofotos (selfies ${ }^{5}$ ), imágenes con amigos o familiares, escenarios naturales, espacios públicos, entre otras cosas.

En las imágenes se observa que mediante la plataforma cruzan la frontera entre lo privado y lo público. El compartir imágenes desde recámaras o dentro de las casas - tanto de mujeres como de hombres wayuu, wiwas y afrocolombianas, así como de jóvenes umareños de adscripción zapoteca, tacuate, mixteca y afromexicana, muestra sus mundos "privados"- Pero ponen candados a ciertas personas: "yo ya aprendí, en fotos [sic] comprometedoras no dejo que mi familia las pueda ver, mis tías sobre todo", menciona una universitaria zapoteca lesbiana.

Algunas fotos de perfil de mujeres wayuus eran de su niñez. Además de la imagen en sí, mostraban dos cosas más: la digitalización de fotos impresas para ser colocadas en plataformas digitales, y autoadscripciones de etnicidad, de región o de nacionalidad. De esta manera, perfilan una representación de sí mismas con diversas escalas de pertenencia a sus comunidades: étnica, regional y nacional, como wayuu, guajiras y colombianas.

También se encuentran casos de quienes editan las fotos mediante el uso de las propiedades de diversas aplicaciones, como sucede con fotografías en donde añaden filtros que apropian de Snapchat o Instagram. Esto es importante porque la triangulación o sincronización que realizaban para agregar los filtros en sus muros de Facebook, muestra la relevancia de la agencia juvenil en la cultura digital. Los y las jóvenes están apropiando la plataforma como un microsistema de tránsito y redistribución interconectada con otros microsistemas, al ser parte del ecosistema digital (Van Dijk, 2016).

La apropiación de las aplicaciones da cuenta de su uso para actividades de ocio y tiempo lúdico, como un rasgo de la cultura digital, pero también esta apropiación responde a los requerimientos de la cultura escolar. Es decir, mediante el descubrimiento de las funciones del sistema de diversas plataformas, los y las jóvenes van conociendo formas de editar, que luego incorporan a sus trabajos académicos. Mientras que se piensa desde la cultura escolar que lo digital quita el tiempo, las diversas estrategias juveniles muestran que la lógica de involucramiento no es de abajo hacia arriba, sino que el capital digital juvenil es una distinción generacional que se aprovecha para asuntos escolares formales.

\section{La autopresentación del yo}

Facebook se dinamiza con hipernarrativas que surgen en presente continuo. ¿Qué estás pensando?, es la pregunta que encabeza la cascada de la plataforma, distinto a Twitter, donde la pregunta es ¿qué está pasando? En términos generales, mientras Facebook es un muro biográfico para compartir estados y emociones con amigos, Twitter es un microblog donde se comparte lo que está sucediendo en el mundo al momento. En términos numéricos, aunque Facebook se centra en el tipo de acciones comunicativas de uno a muchos, la red social no descarta otras estrategias, ya que permite formas comunicativas alternas que pueden ser de uno a uno, o de muchos a muchos, como sucede con otras formas de comunicación digitales (Salmons, 2016).

Algo que puede dinamizar los muros de forma performativa es la autofoto o selfie. Esa autoexposición del yo, es una foto que se hace "de mí para el mundo"; los destinatarios son los otros miembros de la red en un circuito de gratificaciones y comentarios sin un ritmo lineal. Como lo comenté, con la porosidad de lo público y privado, "todo es accesible a la mirada", pues encontré en las pantallas que todo se aglutina "como un aleph contemporáneo" (Díaz, 2015, pp. 24-25). Si en el Aleph borgiano se concentran los actos, lo tiempos y los puntos, en el muro la autopresentación del yo, a través de una foto cotidiana, genera gratificaciones y comentarios en presente continuo, las cuales van condesando sentidos y saberes. 
Como lo proponen distintos autores, el acercamiento etnográfico de la tecnología se entiende en los usos (Hine, 2004; Salmons, 2016); por esa razón, después de un tiempo decidí tomarme una selfie para "hacer una experiencia directa en el campo" (Ardévol, 2016, p. 27). Los resultados arrojaron más de 120 gratificaciones y más de quince comentarios. Entre las reacciones, me comentaron que me había tomado una selfie "como hace la chaviza", adjudicando esa práctica a los jóvenes. Con esto, logré captar uno de los sentidos de la cultura digital: que lo emocional en la inmediatez está imbricado con lo efímero, con el sarcasmo, la ironía, con la adulación, así como con violencias naturalizadas. En las hipernarrativas, el usuario es el mensaje, en dialéctica con otros usuarios, pues aunque se construyen significados individualizados están circundados por interpretaciones múltiples.

Después de mi experiencia, una joven afrodescendiente mexicana compartió una selfie que se había tomado dentro de una casa. Ella decidió solo mostrar el rostro. Obtuvo más de 430 gratificaciones en un día, de las cuales casi 400 fueron "me gusta", 30 "me encanta" y un "me asombra". Además, recibió 29 comentarios, de los cuales los que más se repetían era "Hermosa”, aunque también "me encantas", "chula”, "guapa”. Hubo percepciones de apariencia: "pareces brasileña”. Provocó reacciones en los otros: "me haces sonreír", y no faltaron las preguntas: “¿Cuándo vienes al rancho?”; "por qué solo me ves y no me hablas”.

Ella respondió de forma escrita o también se limitó a dar "me gusta". En un comentario en el que le mandaban una imagen de un perro con flores, ella dio un me gusta, mientras que otro amigo le dio una gratificación negativa a la imagen: "me enoja", fue el emoji utilizado.

Por su parte, una joven wayuu que también se tomó una selfie obtuvo cinco gratificaciones en el día. Todas con el emoticón de "me gusta”. Además, recibió dos comentarios, en uno no respondió y en otro que decía "hermosaaa, mani"; ella respondió con dos emojis de los que mandan besos.

Las autofotos son de los contenidos digitales de la plataforma que mayores comentarios y gratificaciones reciben. Son la carta de presentación y de actualización del yo. Las reacciones pueden visibilizar relaciones de parentesco: “es de familia”; ubicaciones: “es en la sala de la casa, ¿verdad?; temporalidad: “¡estás allí?”, “¡sigues allí ?”. Además, la autofoto constituye la representación constante del agente en la vida digital, pues actualiza quienes, dónde y cómo están siendo en ese momento. Al escoger la foto que se sube, escogemos quiénes somos, quiénes queremos ser y quienes estamos siendo. Si la autopresentación es performativa, con las hipernarrativas podemos ubicar cómo somos vistos, independientemente de si así queremos ser vistos, porque requiere de los otros para construirse como un objeto digital que genera flujos performativos.

Sin embargo, no se puede afirmar que las autofotos o selfies y la vida digital sean el lado banal y contrario a lo que somos cara a cara, porque sería quitar del centro que lo digital tiene sus propias dinámicas y que las experiencias digitales están situadas en contextos espaciotemporales específicos. En el fondo es "como la vida misma”, pero en un nuevo formato; es la vida misma en formato digital.

\section{Conclusiones}

Las juventudes universitarias indígenas y afrodescendientes muestran en los usos y las apropiaciones de Facebook, que hacer parte de las culturas digitales no se traduce en identificaciones y repertorios uniformes. Sus prácticas y saberes permiten conocer que, aunque el algoritmo propone, el sujeto dispone. Las experiencias juveniles enseñan identificaciones multirreferenciales, que no diluyen sus identificaciones de etnicidad ni de género.

El tipo de infraestructura muestra el desigual acceso a la conectividad en América Latina, y más si eres joven, indígena o afrodescendiente, mujer, homosexual, universitario y otras tantas posiciones situadas. El ser universitario o universitaria indígena no implica que sus flujos de sentido están interconectados con las islas de socialidad juvenil presenciales y digitales. Su articulación dinámica muestra las culturas digitales juveniles. 
En diversas situaciones sociodigitales se reconocen y reafirman sus identificaciones de etnicidad, género y generación, pues sus muros están siendo dinamizados con otros jóvenes con quienes se identifican y difieren. No hay una hegemonía de lo escrito en sus hipernarrativas, pues lo oral, lo visual y lo sonoro forman parte de sus repertorios de interacción (Martín-Barbero, 2002).

Resaltan los préstamos transculturales, pero también las tensiones que muestran tanto estigmas como resistencias. Aunque surjan estigmas adultocéntricos sobre el Facebook, este espacio es una arena de intercambio de saberes y de posicionamientos juveniles heterogéneos.

El ser universitario e internauta, "en sí mismo" altera cualquier imagen de esencialización de la juventud indígena y afrodescendiente. Al estar siendo parte de las culturas digitales van construyendo contrarrelatos que revelan la agencia juvenil en trayectorias de vida densas e intensas, tanto en las relaciones cara a cara como en las que tienen lugar en Facebook. De allí, la justificación de una agenda de estudios comparativos que pongan en el centro a las y los jóvenes universitarios indígenas y afrodescendientes en América Latina.

\section{Agradecimientos}

Agradezco a Néstor Díaz y a José María Figueiras Nodar por su ayuda y las ideas que aportaron para la realización de este artículo.

\section{Referencias}

Ardévol, E. (2016). Big data y descripción densa. Virtualis. Revista de Cultura Digital, 7(14), 14-37. http://aplicacio nes.ccm.itesm.mx/virtualis/index.php/virtualis/article/view/186/181

Bensa, A. (2015). Después de Lévi-Strauss. Por una antropología de escala humana. Fondo de Cultura Económica.

Díaz, Y. (2015). Todo retrato es pornográfico. Conaculta-Fondo Editorial Tierra Adentro.

Hine, C. (2004). Etnografia virtual. UOC Editorial.

Lagarde, M. (2011). Los cautiverios de las mujeres. Madresposas, monjas, putas, presas y locas. UNAM-Siglo XXI.

Lasén, A. (2000). A contratiempo. Un estudio de las temporalidades juveniles. Centro de Investigaciones SociológicasSiglo XXI.

Lasén, A. y Puente, H. (2016). La cultura digital. En D. López, Tecnologías sociales de la Comunicación. Materiales Docentes de la UOC, Módulo Didáctico 3 (pp. 1-45). UOC.

Martín-Barbero, J. (2002). Oficio de cartógrafo. Travesías latinoamericanas de la comunicación en la cultura. Fondo de Cultura Económica.

Pink, S., Horst, H., Postill, J., HJort, L., Lewis, T., y Tacchi, J. (2016). Digital Ethnography. Principles and Practice. SAGE.

Reguillo, R. (2010). Presentación. En R. Reguillo (coord), Los jóvenes en México (pp. 9-13). Fondo de Cultura Económica-CNCA.

Restrepo, E. (2012). Intervenciones en teoría cultural. Universidad del Cauca.

Reygadas, L. (2004). Más allá de la clase, la etnia y el género: acciones frente a diversas formas de desigualdad en América Latina. Alteridades, 14(28), 91-106. https://alteridades.izt.uam.mx/index.php/Alte/article/view/303

Ricaurte, P y Ortega, E. (2010). Facebook o los nuevos rostros de la socialidad. Virtualis. Revista de Cultura Digital, 14. https://www.revistavirtualis.mx/index.php/virtualis/article/view/30

Rogers, R. (2009). The end of the virtual-digital methods. Inaugural Speech, Chair, New Media \& Digital Culture, University of Amsterdam, Amsterdam, Países Bajos. https://dare.uva.nl/search?identifier=024001b1-050c-42 d9-bf2d-a56f186deflf

Rogers, R. (2013). Digital methods. MIT.

Salmons, J. (2016). Doing qualitative research online. SAGE. 
Saraví, G. (2015). Juventudes fragmentadas. Socialización, clase y cultura en la construcción de la desigualdad. FlacsoCiesas.

Turner, V. (1974). Dramas, fields, and metaphors. Cornell University Press.

Urteaga, M. (2011). La construcción juvenil de la realidad. Jóvenes mexicanos contemporáneos. Universidad Autónoma Metropolitana-Juan Pablos Editor.

Van Dijk, J. (2016). Cultura de la conectividad. Siglo XXI.

\section{Notas}

* Artículo de Investigación. Este trabajo es resultado de la tesis doctoral titulada L@s internautas del Pacifico mexicano y del Caribe colombiano: jóvenes universitari@s indígenas y cultural digital, realizada en el posgrado de Estudios Latinoamericanos de la Universidad Nacional Autónoma de México (UNAM), que contó con financiamiento de Conacyt.

1 En este trabajo busqué no sobrerrepresentar a los varones como condición de los jóvenes, por esto, me situé entre hombres y mujeres jóvenes de diversas autoadscripcciones sexo-genéricas.

2 Consiste en dos pensamientos distintos que se activan con una frase, que se dinamiza en función de la interacción. Al ser una proposición dinámica y no organicista "los dos pensamientos están activos juntos, engendran pensamiento en su conectividad" (Turner, 1974, p. 6).

3 Eduardo Restrepo (2012) crítica las visiones culturalistas que asumen la cultura como una isla autónoma. Con esta postura, se aceptaría la falta de contacto entre microespacios y que la homogeneidad cultural no es real, sino imaginada por los antropólogos. La metáfora que propongo es la de ver los microespacios como fronteras y no como territorios autónomos. Así, se plantea que el conjunto de islas constituyen un archipiélago dinámico, transitado por jóvenes, que llevan y traen transacciones culturales presenciales, e interacciones digitales ubicuas. Con esto, creo romper la imagen de isla como algo apartado y, más bien, como algo en movimiento dinamizado por jóvenes.

4 Representan un conjunto de datos que se tienen en un campo digital determinado, siendo la labor del investigador ir más allá del conjunto de datos, en general, para construir datos situados, de acuerdo con las conexiones de sentido que se establezcan entre el fenómeno de estudio, las personas y los intereses de cada investigación.

5 Autoimagen o autofoto representativa del yo contemporáneo en las redes sociodigitales, que se toma con una cámara digital o teléfono inteligente para ser compartida en sus biografías o muros de los distintos perfiles de las redes sociales.

\section{Licencia Creative Commons CC BY 4.0}

Cómo citar este artículo: Meneses Cárdenas, J. A. (2020). Archipiélago juvenil: jóvenes indígenas y cultura digital. Universitas Humanistica, 89. https://doi.org/10.11144/Javeriana.uh89.ajji 